\title{
Anxiety and Depression Levels and Their Relation to the Severity of Chronic Obstructive Pulmonary Disease in Patients Who Un- derwent Pulmonary Rehabilitation Program
}

\section{Rafael Machado de Souza ${ }^{1}$, Daniela Bervian Linck ${ }^{2}$, Cassia Cinara da Costa ${ }^{3 *}$, Maria Lucia Langone ${ }^{4}$ and Paulo Jose Zimermann Teixeira ${ }^{5}$}

${ }^{1}$ Center of Health Sciences and Physical Educator of the Pulmonary Rehabilitation Program, Feevale University, Brazil

${ }^{2}$ Department of Physical Education, Feevale University, Brazil

${ }^{3}$ Center of Health Sciences and Coordinator of the Respiratory Rehabilitation Program, Feevale University, Brazil

${ }^{4}$ Center of Health Sciences, Sinos Valley University, Brazil

${ }^{5}$ Department of Medical Clinic, Pulmonology, Feevale University, Brazil

*Corresponding author: Cassia Cinara da Costa, Professor, Center of Health Sciences and Coordinator of the Respiratory Rehabilitation Program, Feevale University, Rio Grande do Sul, Av. Pedro Adams Filho, 6092/402, Novo Hamburgo, RS, Brazil,E-mail: cassiac@feevale.br

\begin{abstract}
Chronic obstructive pulmonary disease is a preventable and treatable disease characterized by persistent airflow limitation, usually progressive and associated with an abnormal lung inflammatory response to inhalation of particles or toxic gases. Exacerbations and comorbidities contribute to the overall worsening of the patient. The aim of this study was to assess the anxiety and depression levels and their relation to disease severity, in addition to analyzing the correlation between anxiety and depression and functional capacity by 6MWT before and after PRP. This is a retrospective study that analyzed 163 patients between 2008 and 2014 with mean age of $64.7 \pm 7.8$ years. From those, $64.4 \%$ (105) were male and $35.6 \%(58)$ were female. Concerning the spirometry, the following averages were found: $65.39 \pm 21.84$ for CFV, $42.82 \% \pm 17.96$ of predicted VEF1 values and $53.79 \% \pm 17.02$ for VEF1/CFV. The initial and final average distance traveled in the 6MWT was $405.08 \mathrm{~m} \pm 99.41 \mathrm{~m}$ vs. $459.92 \mathrm{~m} \pm 99.24 \mathrm{~m}$, respectively. Patients had and initial and final mean score of $9.86 \pm 6.55$ vs. $7.53 \pm 7.24$ for BAl results. BDI results were $11.25 \pm 7.98$ vs. $8.23 \pm 6.81$. Therefore, it can be concluded that, by the end of PRP, patients modified their depression levels, passing from mild to minimal category. As for the anxiety test, there was a decrease in the score; however, they remained in the same category (minimal). Comparing the averages of pre and post rehabilitation moments, significant results can be observed as for the improvement of 6MWT, BAI and BDI. However, none of these variables (BAI, BDI and FEV1/FVC) are correlated with 6MWT.
\end{abstract}

\author{
Keywords \\ Anxiety, Depression, COPD, Pulmonary rehabilitation program
}

\section{Introduction}

COPD is a preventable and treatable disease characterized by persistent airflow limitation, usually progressive and associated with accentuated chronic inflammation in the airways and lung in response to inhalation of particles or toxic gases. Exacerbations and comorbidities contribute to the overall worsening of the patient [1]. COPD is usually accompanied by multiple comorbidities. Anxiety and depression are common associations and result in aggravating the conditions of patients [2]. Because of dyspnea, the patient needs to alter its lifestyle, as it becomes unable to perform activities of daily living [3]. COPD by itself is an incapacitating disease, allied with anxiety and depression it becomes even more dangerous, transposing its limitations to emotional, marital and sexual relationships, in leisure and professional activities. Hence, many patients become dependent on relatives, which reinforce the feeling of being incapacitated [4].

Previous studies identified patients that reported: 
preoccupation with death, death wish, fear of feeling pain and unable to bear the suffering imposed by a dyspnea crisis [5]. Pulmonary rehabilitation programs are a therapeutic option, but not pharmacological, which improves muscle strength and aerobic endurance training. Moreover, they assist on patient's understanding of the disease and provide psychological support in groups. Therefore, patients realize that there are other people like them going through the same difficulties, or even more attenuated, which may eventually reduce levels of depression [6-9].

Peripheral muscle strength and endurance, capacity exercises and quality-of-life are compromised in patients with COPD [10], as they have smaller proportions of type I oxidative fibers [11]. Furthermore, it has been shown that the worse the functional performance of the lower extremities in the SPPB (Short Physical Performance Battery) test, which is a battery of tests that assess physical and functional performance of the lower extremity, the smaller the distance traveled in the Six-Minute Walk Test (6MWT), the greater the dyspnea in activities of daily living, and consequently, the higher the BODE (body mass index airway obstruction, dyspnea and exercise capacity) index of COPD severity. Other studies reported the importance of assessing strength and endurance of lower extremities in PRP [6,12-14]. Another study emphasizes the reliability of 6MWT to evaluate functional capacity of the lower extremities [13].

The aim of this study was to assess the anxiety and depression levels and their relation to disease severity, in addition to analyzing the correlation between anxiety and depression and functional capacity by 6MWT before and after PRP.

\section{Materials and Methods}

This is a before and after type of retrospective study, in which a total of 455 individuals were included from 2008 to 2014 . There was great sample loss due to patients' dropout of PRP or with incomplete information in database $(n=292)$. Above all, only 176 patients had their complete data in the database, of which only 163 had all the inclusion criteria of Universidade Feevale of Novo Hamburgo - RS in the period from May 2007 to December 2011. COPD diagnosis was performed according to GOLD (Global Initiative for Chronic Obstructive Lung Disease), using the clinical history, physical exam and confirmation of airflow obstruction through the ratio of forced expiratory volume in the first second $\left(V_{1} F_{1}\right)$ by Forced Vital Capacity (FVC) less than $70 \%$ of predicted value. All patients had moderate to serious COPD defined by a $\mathrm{FEV}_{1}<60 \%$ of the predicted value after using bronchodilator. An Office Excel ${ }^{\oplus}$ spreadsheet was elaborated from a Pulmonary Rehabilitation Program (PRP) database. This spreadsheet contained information of individuals of both sexes, complete name, COPD diagnosed, gender, pulmonary capacities (FVC; FEV 1 in liters and percentage, $\mathrm{FEV}_{1}$ /FVC), 6MWT (pre and post), Beck Anxiety Inventory (BAI) and Beck Depression Inventory (BDI) (pre and post). Thus, all patients who had complete data, before and after rehabilitation, were included in the study. Those who lacked some information in the database or did not have COPD were excluded from the study.

The Pulmonary Rehabilitation Program (PRP) consisted of a 12-week multidisciplinary program, in which patients were followed up by these professionals: doctor, psychologists, nutritionists, nurses and the physical exercise program was supervised by physiotherapists and physical educators.

Patients were interviewed about physical activity when they started the PRP and all answered that due to dyspnea none of them practiced it. The program happened three times a week; Mondays, Wednesdays and Fridays in the morning for $2 \mathrm{~h}$, being divided into: warm up, aerobic exercises, endurance and stretching. Functional diagonal movements for Upper Extremities (UE) and Lower Extremities (LE) were performed during warm up. The aerobic exercises were performed in a treadmill (Inbrasport Mod 7.5) with progressive increase of time from 5 to 30 minutes of walking, and increased speed, according to the subjective perception of moderate effort (BORG scale) [15], without tilting it. The variables measured were: heart beat frequency, peripheral oxygen saturation by the oxymeter from Morrya ${ }^{\circ}$ brand 1001 model and BORG scale to measure the perception of patient in regards to dyspnea in each minute. When there was a saturation drop below $90 \%$, these patients received oxygen supplementation through nasal catheter in order to maintain the oxygen saturation $[16,17]$.

As for strength training for the upper and lower extremities, the following exercises were performed in a bodybuilding equipment from Aston Sportmania brand: pulldowns, knee extension and flexion (leg extension/ leg curl), seated bench press machine, supine bench press, trunk flexion (abdominal) performed in a 45 degree angle bench, shoulder horizontal extension (dorsal flying) and free weights (dumbbells and ankle weights) through elbow flexion-extension exercises in bipedal position (biceps curls and triceps press), shoulder abduction (side elevation) and plantar flexion [18].

Prior to the 1 Repetition Maximum (1RM), patients underwent a week of training adaptation, with three sessions, a series of 20 repetition for each exercise, with the minimum possible weight. At the end of adaptation, patients underwent the $1 \mathrm{RM}$ test to determine the intensity of strength training, and a re-test was not performed for the beginning of training. Afterwards, the training weight was defined, which varies incrementally by starting between 50 and $60 \%$ of 1 RM during the first two weeks and there was a gradual weekly increase until $85 \%$ of 1 RM, according to the patient's tolerance. All training was performed with 2 series of $8-12$ repetitions 
Table 1: Basal characteristics of the 163 patients with COPD treated in the pulmonary Rehabilitation Program.

\begin{tabular}{|c|c|c|}
\hline Variables & n (\%) & $M \pm S D$ \\
\hline Sample & $163(100)$ & \\
\hline Male & $105(64.4)$ & \\
\hline Female & $58(35.6)$ & \\
\hline \multicolumn{3}{|l|}{ COPD } \\
\hline Mild & $9(5.5)$ & \\
\hline Moderate & $53(32.5)$ & \\
\hline Severe & $58(35.6)$ & \\
\hline Very severe & $43(26.4)$ & \\
\hline \multicolumn{3}{|l|}{ Lung function } \\
\hline FVC L & & $2.31 \pm 0.93$ \\
\hline FVC \% foreseen & & $65.39 \pm 21.84$ \\
\hline $\mathrm{FEV}_{1} \mathrm{~L}$ & & $1.19 \pm 0.58$ \\
\hline $\mathrm{FEV}_{1} \%$ foreseen & & $42.82 \pm 17.96$ \\
\hline $\mathrm{FEV}_{1} / \mathrm{FVC}$ & & $53.79 \pm 17.02$ \\
\hline \multicolumn{3}{|l|}{ 6MWT } \\
\hline Before & & $405.08 \pm 99.41$ \\
\hline After & & $459.92 \pm 99.24^{*}$ \\
\hline \multicolumn{3}{|l|}{ BDI } \\
\hline Before & & $11.25 \pm 7.98$ \\
\hline After & & $8.23 \pm 6.81^{*}$ \\
\hline \multicolumn{3}{|l|}{ BAI } \\
\hline Before & & $9.86 \pm 6.55$ \\
\hline After & & $7.53 \pm 7.24^{*}$ \\
\hline
\end{tabular}

*Significance of $p<0.001$ for before and after the 12-week Pulmonary Rehabilitation Program.

Anxiety and depression had a significant reduction of their levels $\left(9.86 \pm 6.55\right.$ vs. $7.53 \pm 7.24^{*} ; 11.25 \pm 7.98$ vs. $8.23 \pm 6.81^{*}$, respectively) when compared to before and after PRP. Another variable that had a significant improvement was the functional performance, which can be evaluated by the increase of distance traveled in the 6MWT (405.08 \pm 99.41 vs. 459.92 $\left.\pm 99.24^{*}\right)$

per muscle group, according to the patient's tolerance referred by the Borg scale. Patients were advised to perform passive breathing, inhale during the eccentric phase of contraction and exhale during the concentric phase with pursed-lips, i.e. with half-closed lips during the execution of the movement, at the same speed $[15,18,19]$.

In addition to these activities, patients attended weekly educational lectures with the team and a support group with a Psychologist. BAI and BDI, both with 21 items with four alternatives each, were used to measure the levels of anxiety and depression in these patients. The referred alternatives are: level of depression minimal (score from 0 to 11), mild (from 12 to 19), moderate (from 20 to 35 ) and severe (from 36 to 63 ); levels of anxiety minimal (score from 0 to 10), mild (from 11 to 19), moderate (from 20 to 30 ) and severe (from 31 to 63$)[20]$.

All patients signed the Free and Clarified Consent Term. This research started after being approved by the Committee of Ethic of the Universidade Feevale under the report number 4.08.03.08.1239.

The variables studies are presented in its mean values \pm standard deviation, also descriptive statistics by abso- lute $(\mathrm{n})$ and relative (\%) frequencies distribution, minimum and maximum values, arithmetic means and its respective standard deviation. The scores of this study's variables were tested in regards to normality by the Kolmogorov-Smirnov protocol and all variables showed normal distribution. Comparisons of score means were performed by Student's t test for dependent samples (pairwise). Cause-effect relationships between the variables were analyzed by the correlation test $(r)$ of Pearson-Bravais. All statistic procedures were executed in SPSS software (Version 17.0), with significance level of $p \leq 0.05$.

\section{Results}

A total of 163 patients participated in this study, with mean age of $64.7 \pm 7.8$ years. The majority, $64.4 \%$ (105), represented the male gender and $35.6 \%(58)$ represented the female gender. The sample was stratified according to the staging of the disease. The following results were found: $5.5 \%$ (9) had mild COPD, 32.5\% (53) moderate COPD, $35.6 \%$ (58) severe COPD and $26.54 \%$ (43) very severe COPD. These characteristics are represented in (Table 1).

Anxiety and depression had a significant reduction of their levels $\left(9.86 \pm 6.55\right.$ vs. $7.53 \pm 7.24^{*} ; 11.25 \pm 7.98$ vs. $8.23 \pm 6.81^{*}$, respectively) when compared to before and after PRP. Another variable that had a significant improvement was the functional performance, which can be evaluated by the increase of distance traveled in the $6 \mathrm{MWT}\left(405.08 \pm 99.41\right.$ vs. $\left.459.92 \pm 99.24^{*}\right)$.

By analyzing (Table 2), we can identify that, when we stratified patients by disease staging, there was a significant improvement in the anxiety and depression levels in all groups, except for the mild group, which was the one with the fewest number of patients and with no significant changes of the disease. Another important factor in this group was the distance traveled in the 6MWT, in which no significant increase was seen, probably because they could already walk more than the other groups in the beginning of PRP $(455.0 \pm 88.7$ vs. $478.1 \pm$ 84.8) (Table 3).

No correlation was observed between anxiety and depression levels with the analyzed performance variables of $6 \mathrm{MWT}$, in any staging of the disease.

\section{Discussion}

This study aimed to evaluate the anxiety and depression levels and their relation to the severity of the disease, in addition to analyzing the correlation between anxiety and depression and functional capacity by 6MWT before and after PRP.

COPD is frequently associated to other comorbidities, which has a significant impact on its prognosis. Among these comorbidities are: cardiovascular diseases, lung cancer, metabolic syndrome, diabetes mellitus, depression and anxiety [1]. 
Table 2: Result of the comparison of means between the before-after moments of the Pulmonary Rehabilitation Program-PRP, separated by COPD stage.

\begin{tabular}{|c|c|c|c|c|}
\hline \multicolumn{5}{|l|}{ Moment } \\
\hline Staging & Variables & Before $M \pm S D$ & After $M \pm S D$ & $\mathbf{p}$ \\
\hline Mild & Walk Test (m) & $455.0 \pm 88.7$ & $478.1 \pm 84.8$ & 0.342 \\
\hline \multirow{2}{*}{$n=9$} & BAI (scores) & $12.11 \pm 8.58$ & $8.44 \pm 4.82$ & 0.206 \\
\hline & BDI (scores) & $12.44 \pm 5.34$ & $3.56 \pm 3.00$ & $0.005^{* *}$ \\
\hline Moderate & Walk Test (m) & $432.1 \pm 95.3$ & $485.7 \pm 88.3$ & $<0.001^{* *}$ \\
\hline \multirow{2}{*}{$n=53$} & BAI (scores) & $9.91 \pm 6.86$ & $7.74 \pm 7.33$ & $0.025^{*}$ \\
\hline & BDI (scores) & $10.43 \pm 7.94$ & $8.19 \pm 5.26$ & $0.043^{*}$ \\
\hline Severe & Walk Test (m) & $383.6 \pm 99.1$ & $439.7 \pm 96.6$ & $<0.001^{* *}$ \\
\hline \multirow{2}{*}{$n=58$} & BAI (scores) & $8.86 \pm 5.65$ & $6.57 \pm 6.97$ & $0.008^{* *}$ \\
\hline & BDI (scores) & $10.97 \pm 7.75$ & $7.74 \pm 7.28$ & $0.001^{\star \star}$ \\
\hline Very Severe & Walk Test (m) & $390.3 \pm 98.7$ & $451.6 \pm 112.9$ & $<0.001^{* *}$ \\
\hline \multirow{2}{*}{$n=43$} & BAI (scores) & $10.67 \pm 6.85$ & $8.40 \pm 7.93$ & $0.037^{*}$ \\
\hline & BDI (scores) & $12.40 \pm 8.85$ & $9.91 \pm 7.95$ & $0.03^{*}$ \\
\hline
\end{tabular}

$M=$ mean; $S D=$ standard deviation; $\left({ }^{* *}\right)$ significant $p<0.01 ;\left({ }^{*}\right)$ significant $p<0.05$.

Table 3: Correlation $(r)$ between the 6MWT variation with the variations of BAI and BDI, in general and by COPD staging.

\begin{tabular}{|c|c|c|c|c|c|c|c|c|c|c|}
\hline & \multicolumn{2}{|c|}{$\begin{array}{l}\text { General } \\
n=163\end{array}$} & \multicolumn{2}{|l|}{$\begin{array}{l}\text { Mild } \\
n=9\end{array}$} & \multicolumn{2}{|c|}{$\begin{array}{l}\text { Moderate } \\
n=53\end{array}$} & \multicolumn{2}{|c|}{$\begin{array}{l}\text { Severe } \\
n=58\end{array}$} & \multicolumn{2}{|c|}{$\begin{array}{l}\text { Very Severe } \\
n=43\end{array}$} \\
\hline & BAI & BDI & BAI & BDI & BAI & BDI & BAI & BDI & BAI & BDI \\
\hline$r$ & -0.04 & 0.023 & 0.092 & 0.542 & -0.207 & 0.003 & 0.099 & -0.084 & -0.095 & 0.025 \\
\hline$p$ & 0.616 & 0.77 & 0.813 & 0.132 & 0.137 & 0.98 & 0.459 & 0.531 & 0.543 & 0.874 \\
\hline
\end{tabular}

$p=$ probability value; $r=$ Pearson-Bravais correlation value .

In this study, it was possible to observe that PRP was a very significant intervention, as patients had their anxiety and depression levels reduced. Anxiety occurs in the majority of COPD patients, and at the beginning of PRP they had more elevated levels. Nonetheless, after 12 weeks of PRP, a significant reduction of anxiety was observed. Another study that evaluated 125 patients after strength and endurance combined training found similar results to ours, with decrease of anxiety. On the contrary, a study performed with 81 men with COPD found no changes in anxiety after 8 weeks of twice a week-PRP $[21,22]$. However, the evaluated group in the present study had the minimal classification for anxiety and with the improvement in physical conditioning there was a decrease of the sensation of dyspnea to mild exertion, which consequently decreases the sensation of anxiety.

Our group has also evaluated depression, which is frequently associated to patients with COPD. A significant decrease in depression was identified; similar to what was found by another study that underwent patients with COPD to eight weeks of physical exercises twice a week [22]. A study with 234 patients with COPD observed a significant decrease in BDI score after pulmonary rehabilitation [21]. A significant decrease in depression was also verified after PRP in a study with 125 patients with COPD [18]. Importantly, this study sample had a decrease in the classification of depression from mild to minimal after the 12-week rehabilitation. Therefore, COPD promotes social isolation in most patients and the social interaction stimulated during PRP may have helped in reducing depression levels in these patients.
Unlike the present study, another study that analyzed the level of depression in 277 individuals found a total BDI score of 14 (2-34) for mild and moderate staging, and the total score for severe and very severe staging reached $21(0-42)$ [22].

Patients with COPD had a decrease in the physical capacity that directly reflects the decrease of walking capacity. Thus, after 36 sessions of endurance and strength interval continuous training, the patients had a significant improve in the walking capacity in 54 meters $(p<0.05)$. A study with 36 patients with COPD found similar results; however, patients underwent 20 sessions of cycle ergometer training $[23,24]$.

Fifty-four patients who underwent 36 sessions of strength and endurance training showed an improvement of 25 meters $(p<0.01)$ [25]. An endurance training protocol of 40 sessions from another study demonstrated an improvement of 32 meters $(p<0.05)$ [26]. An increase of 34 meters was observed in 234 patients after pulmonary rehabilitation program with combined training. Moreover, a 12-month observational and prospective study had an improvement of 84 meters, with a three times a week-strength and endurance training and additional 30 sessions of endurance and mobility exercises in the pool [27]. PRP with different strategies of physical training promotes improvement in functional capacity, which reflects on the increase of distance traveled in the walk test after pulmonary rehabilitation. Also, improvement of physical conditioning promotes greater exercise tolerance and reduces dyspnea on mild exertion. 
When patients were classified by staging of COPD, statistically significant changes were observed for: $6 \mathrm{MWT}$, depression and anxiety in patients with moderate, severe and very severe COPD. However, patients with mild COPD had no significant changes in walking capacity and anxiety after pulmonary rehabilitation. In another study with 101 patients with COPD, significant alterations for depression were demonstrated by reduced BDI scores in all staging of the disease [28].

In a study that evaluated 112 patients in severe and very severe staging, before and after PRP, observed an improvement in 6MWT around 80 meters and in the feeling of anxiety [29]. By analyzing some studies, we could identify that the very severe staging demonstrated greater evolution in traveled meters at the end of PRP $[21,30,31]$.

The use of Beck inventory for anxiety and depression can be reported as a limitation of this study, as the Spielberger State-Trait Anxiety Inventory (SSTAI) has been used in some studies with lung disease patients.

Concluding, at the end of PRP patients reduced their depression and anxiety levels. Comparing the means of pre- and post-rehabilitation moments, significant results in regards to $6 \mathrm{MWT}, \mathrm{BAl}$ and $\mathrm{BDI}$ improvement can be observed. Nonetheless, none of these variables (BAI, $\mathrm{BDI}$ and FEV1/FCV) are correlated to 6MWT. Therefore, further studies with larger samples for data correlation are suggested.

\section{References}

1. GOLD (2016) Global Initiative for Chronic Obstructive Lung Disease. Global strategy for the diagnosis, management, and prevention of chronic obstructive pulmonary disease.

2. Maurer J (2009) Anxiety and depression in COPD: Current understanding, unanswered questions, and research needs. Revista Portuguesa de Pneumologia 15: 740-742.

3. Nyssen SM, Santos JG, Barusso M, Oliveira ADJ, Di Lorenzo VAP, et al. (2013) Levels of physical activity and predictors of mortality in COPD. J Bras Pneumol 39: 659-666.

4. Sociedade Brasileira de Pneumologia e Tisiologia (2006) Consenso Brasileiro sobre Doença Pulmonar Obstrutiva Crônica - DPOC. Revisão de alguns aspectos de epidemiologia e tratamento da doença estável.

5. Cheik NC, Reis IT, Heredia RAG, Ventura ML, Tufik S, et al. (2003) Efeitos do exercício físico e da atividade física na depressão e ansiedade em indivíduos idosos. $\mathrm{R}$ Bras $\mathrm{Ci}$ e Mov 11: 45-52.

6. Silva JRG, Vasconcelos TB, Macena RHM, Bastos VPD, Morano MTAP, et al. (2013) Analysis of the BODE index in patients with severe COPD undergoing a pulmonary rehabilitation program. Journal of Health and Biological Sciences 3: 108-113.

7. Godoy RF, Teixeira PJZ, Becker B, Michelli M, Godoy DV, et al. (2009) Late repercussions of a pulmonary rehabilitation program on the indexes of anxiety, depression, quality of life and physical performance in patients with COPD. J Bras Pneumol 35: 129-136.

8. Minghelli B, Tome B, Nunes C, Neves A, Simoes C, et al.
(2013) Comparison of anxiety and depression levels among active and sedentary elderly. Archives of Clinical Psychiatry 40: 71-76.

9. Godoy RF (2013) Anxiety, depression and hopelessness in patients with chronic obstructive pulmonary disease. Studies and Research in Psychology 13: 1089-1102.

10. Calik-Kutukcu E, Savci S, Saglam M, Vardar-Yagli N, Inal-Ince D, et al. (2014) A Comparison of muscle strength and endurance, exercise capacity, fatigue perception and quality of life in patients with chronic obstructive pulmonary disease and healthy subjects: a cross-sectional study. BMC Pulm Med 14: 6 .

11. Slot IG, van den Borst B, Hellwig VA, Barreiro E, Schols AM, et al. (2014) The muscle oxidative regulatory response to acute exercise is not impaired in less advanced COPD despite a decreased oxidative phenotype. PLoS One 9: e90150.

12. Silva HE, Zipperer A (2013) The correlation between lower extremity physical functional and severity of chronic obstructive pulmonary disease. Fisioter Mov 26: 379-387.

13. Pessoa BV, Jamami M, Basso RP, Regueiro EMG, Oliveira $A D$, et al. (2013) Comparison of different functional tests of lower limbs in patients with chronic obstructive pulmonary disease: there is concordance between them. Fisioter Mov 26: 491-502.

14. Global Initiative for Chronic Obstructive Lung Disease (2006) Global strategy for the diagnosis, management and prevention of chronic obstructive pulmonary disease.

15. Borg GA (1982) Psychophysical bases of perceived exertion. Med Sci Sports Exerc 14: 377-381.

16. Storer TW (2011) Exercise in chronic pulmonary disease: resistance exercise prescription. Med Sci Sports Exerc 33: 680-692.

17. Nici L, Donner C, Wouters V, Zuwallack R, Ambrosino N, et al. (2006) American Thoracic Society European Respiratory Society Statement on pulmonary rehabilitation. Am J Resp Crit Care Med 173: 1390-1413.

18. Costa CC, Leite B da S, Canterle DB, Souza RM, Machado MLL, et al. (2014) Análise da força, qualidade de vida e tolerância ao exercício na doença pulmonar crônica. Revista Brasileira Ciência e Movimento 22: 27-35.

19. Dantas EHM, Oliveira RJ (2003) Exercício, maturidade e qualidade de vida. $2^{a}$ edição, Rio de Janeiro: Shape.

20. Cunha JA (2001) Manual da versão em português das Escalas de Beck. São Paulo: Casa do Psicólogo.

21. Costa CC, Lermen CA, Colombo C, Canterle DB, Machado ML, et al. (2014) Effect of a Pulmonary Rehabilitation Program on the levels of anxiety and depression and on the quality of life of patients with chronic obstructive pulmonary disease. Rev Port Pneumol 20: 299-304.

22. Ryu YJ, Chun EM, Lee JH, Chang JH (2010) Prevalence of depression and anxiety in outpatients with chronic airway lung disease. Korean J Intern Med 25: 51-57.

23. López-García A, Souto-Camba S, Blanco-Aparicio M, González-Doniz L, Saleta JL, et al. (2014) Effects of a muscular training program on Chronic Obstructive Pulmonary Disease patients with moderate or severe exacerbation antecedents. Eur J Phys Rehabil Med 52: 169-175.

24. Hornikx M, Van Remoortel H, Lehouck A, Mathieu C, Maes $\mathrm{K}$, et al. (2012) Vitamin D supplementation during rehabilitation in COPD: a secondary analysis of a randomized trial. Respir Res 13: 84-89. 
25. Christopher CB (2009) Desensitization to dyspnea in COPD with specificity for exercise training mode. Int $\mathrm{J}$ Chron Obstruct Pulmon Dis 4: 33-43.

26. Lomundal BK, Steinsbekk A (2007) Observational studies of a one year self-management program and a two year pulmonary rehabilitation program in patients with COPD. Int J Chron Obstruct Pulmon Dis 4: 617-624.

27. Tselebis A, Bratis D, Pachi A, Moussas G, llias I, et al. (2013) A pulmonary rehabilitation program reduces levels of anxiety and depression in COPD patients. Multidiscip Respir Med 8: 41-45.

28. Von Leupoldt A, Taube K, Lehmann K, Fritzsche A, Magnussen $H$ (2011) The Impact of Anxiety and Depression on Outcomes of Pulmonary Rehabilitation in Patients With COPD. Chest 140: 730-736.

29. Mescheryakova NN, Belevsky AS, Chernyak AC, Neklyudova CV, Lebedin YS (2012) Physical training is a universal method of pulmonary rehabilitation of patients with chronic obstructive pulmonary disease. Ter Arkh 84: 17-21.

30. Jacome, Cristina (2015) Anxiety and depression in Portuguese patients with chronic obstructive pulmonary disease: a multicentre cross-sectional study. Rev Port Med Geral Fam 31: 24-32.

31. Boer LM, Asijee GM, van Schayck OC, Schermer TR (2012) How do dyspnea scales compare with measurement of functional capacity in patients with COPD and at risk of COPD? Prim Care Respir J 21: 202-207. 